Portland State University

PDXScholar

\title{
Greenhouse Gases and other Airborne Pollutants from Household Stoves in China: a Database for Emission Factors
}

\author{
J. Zhang \\ Robert Wood Johnson Medical School and Rutgers University \\ K. R. Smith \\ Environmental Health Sciences, University of California, Berkeley \\ Y. Ma \\ Tsinghua University, Beijing, China \\ S. Ye \\ Tsinghua University, Beijing, China \\ F. Jiang \\ Tsinghua University, Beijing, China
}

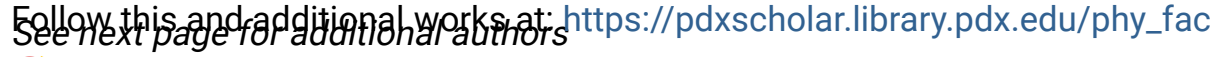

Part of the Physics Commons

Let us know how access to this document benefits you.

\section{Citation Details}

Zhang, J., Smith, K. R., Ma, Y., Ye, S., Jiang, F., Qi, W., ... \& Thorneloe, S. A. (2000). Greenhouse gases and other airborne pollutants from household stoves in China: a database for emission factors. Atmospheric Environment, 34(26), 4537-4549.

This Article is brought to you for free and open access. It has been accepted for inclusion in Physics Faculty Publications and Presentations by an authorized administrator of PDXScholar. Please contact us if we can make this document more accessible: pdxscholar@pdx.edu. 


\section{Authors}

J. Zhang, K. R. Smith, Y. Ma, S. Ye, F. Jiang, W. Qi, P. Liu, M. A. K. Khalil, R. A. Rasmussen, and S. A. Thorneloe 


\title{
Greenhouse gases and other airborne pollutants from household stoves in China: a database for emission factors
}

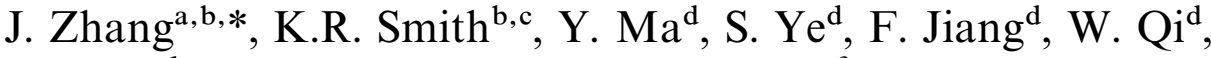 \\ P. Liu ${ }^{d}$, M.A.K. Khalile, R.A. Rasmussen ${ }^{\text {f }}$, S.A. Thorneloe ${ }^{\mathrm{g}}$ \\ ${ }^{a}$ Environmental and Occupational Health Sciences Institute, Robert Wood Johnson Medical School and Rutgers University, \\ 170 Frelinghuysen Road, Piscataway, NJ, USA \\ ${ }^{\mathrm{b}}$ Formerly with Environment Program, East-West Center, Honolulu, Hawaii, USA \\ ${ }^{\mathrm{c} E n v i r o n m e n t a l ~ H e a l t h ~ S c i e n c e s, ~ U n i v e r s i t y ~ o f ~ C a l i f o r n i a, ~ B e r k e l e y, ~ C A, ~ U S A ~}$ \\ ${ }^{\mathrm{d}}$ Tsinghua University, Beijing, China \\ ${ }^{\mathrm{e}}$ Portland State University, Portland, OR, USA \\ ${ }^{\mathrm{f}}$ Oregon Graduate Institute of Science and Technology, Beaverton, OR, USA \\ ${ }^{\mathrm{g}}$ US Environmental Protection Agency, Research Triangle Park, NC, USA
}

Received 1 August 1999; received in revised form 25 September 1999; accepted 28 September 1999

\begin{abstract}
Emissions from household stoves, especially those using solid fuels, can contribute significantly to greenhouse gas (GHG) inventories and have adverse health impacts. Few data are available on emissions from the numerous types of cookstoves used in developing countries. We have systematically measured emissions from 56 fuel/stove combinations in India and China, a large fraction of the combinations in use world-wide. A database was generated containing emission factors of direct and indirect GHGs and other airborne pollutants such as $\mathrm{CO}_{2}, \mathrm{CO}, \mathrm{CH}_{4}, \mathrm{TNMHC}, \mathrm{N}_{2} \mathrm{O}, \mathrm{SO}_{2}, \mathrm{NO}_{x}$, TSP, etc. In this paper, we report on the $28 \mathrm{fuel} /$ stove combinations tested in China. Since fuel and stove parameters were measured simultaneously along with the emissions, the database allows construction of complete carbon balances and analyses of the trade-off of emissions per unit fuel mass and emissions per delivered energy. Results from the analyses show that the total emissions per unit delivered energy were substantially greater from burning the solid fuels than from burning the liquid or gaseous fuels, due to lower thermal and combustion efficiencies for solid-fuel/stove combinations. For a given biomass fuel type, increasing overall stove efficiency tends to increase emissions of products of incomplete combustion. Biomass fuels are typically burned with substantial production of non- $\mathrm{CO}_{2}$ GHGs with greater radiative forcing, indicating that biomass fuels have the potential to produce net global warming commitments even when grown renewably. (C) 2000 Elsevier Science Ltd. All rights reserved.
\end{abstract}

Keywords: Greenhouse gases; Air pollution; Fuel combustion; Domestic fuels; China

\section{Introduction}

It is estimated that biomass combustion contributes $20-50 \%$ of global greenhouse gas (GHG) emissions

\footnotetext{
* Corresponding author. EOHSI, Room 358,170 Frelinghuysen Road, Piscataway, NJ 08854, USA; Tel.: + 1-732-4450158, fax: + 1-732-445-0116.

E-mail address: jjzhang@eohsi.rutgers.edu (J. Zhang)
}

(Crutzen and Andreae, 1990; IPCC 1990). In recent years, the wide uncertainty about the emissions from open large-scale biomass fires has led to a substantial increase in attention given to measuring emissions from wildland fires (Ward and Hardy, 1991), prescribed fires (Cofer et al., 1993), and agricultural burning (Jenkins et al., 1992). A significant fraction of all biomass combustion, however, occurs in enclosed or semi-enclosed small combustion devices such as household stoves for cooking and space heating. For example, about $90 \%$ of the firewood 
(FAO, 1987) and a large fraction of the combusted crop residues are burned in household stoves worldwide, mainly in developing countries (Smith et al., 1993, 1999; Wang, 1994).

Household stoves, although individually small, are numerous and thus have the potential to contribute significantly to inventories of greenhouse gases (GHG), particularly in those many developing countries where household use is a significant fraction of total fuel use. The emissions of greenhouse gases from small-scale combustion of biomass are not well characterized (IPCC, 1997), but are known to be different from open large-scale combustion, such as forest and savannah burning (Levine, 1996). Unfortunately, few measurements have been made to determine emission factors for biomass stoves in developing countries (Smith et al., 1993). Emission factors from other fuels (e.g., coal, kerosene) as commonly used in developing-country households are also not well characterized. Therefore, measurements of GHG emission factors from a range of fuels and combustion devices would remove some of the uncertainty in estimates of global GHG emissions from fuel combustion and also provide a baseline for understanding the potential for reduction in GHG emissions due to various mitigation measures, such as fuel switching, in the household sector.

A pilot study was conducted in Manila, the Philippines, to measure emission factors of a range of GHGs from cookstoves burning biomass, charcoal, kerosene and liquefied petroleum gas (LPG). This pilot study validated a carbon balance approach for determining emission factors for small-scale combustion devices and resulted in tentative, but important, findings regarding carbon dioxide $\left(\mathrm{CO}_{2}\right)$ and non- $\mathrm{CO}_{2}$ GHG emissions from simple household stoves (Smith et al., 1993). To explore these tentative findings further and to produce a comprehensive database of GHG emission factors for a wide range of household stoves commonly used in developing countries, we have tested a total of $56 \mathrm{fuel} /$ stove combinations in India and China for a range of GHGs and other emissions while simultaneously monitoring for fuel and stove parameters. The chosen fuel/stove combinations represent a large fraction of the total in developing countries. The results derived from 28 Indian fuel/stove combinations, along with the details of the methods, have been presented previously (Smith et al., 1999). In this paper, we present a database of emission factors of the following species for the $28 \mathrm{fuel} /$ stove combinations tested in China: $\mathrm{CO}_{2}$, carbon monoxide (CO), methane $\left(\mathrm{CH}_{4}\right)$, total non-methane hydrocarbons (TNMHC), total suspended particles (TSP), and carbon fraction in TSP $\left(\mathrm{C}_{\mathrm{TSP}}\right)$, nitrogen oxide $\left(\mathrm{NO}_{x}\right)$, and sulfur dioxide $\left(\mathrm{SO}_{2}\right)$.

\section{Methods}

\subsection{Fuel/stove combination tested}

The fuel types selected represent those being used commonly in rural households (e.g., crop residue, wood, kerosene, and coal) and those in urban households (e.g., gaseous fuels, coal, and kerosene). The stove types selected were those most typical for burning each type of fuels (i.e., most popular models found in the market or rural households). Since the emission factors are expected to depend upon both fuel types and stove types (Zhang and Smith, 1996), it is most appropriate to discuss the results by "fuel/stove combination". Thus, the fuel/stove combination was treated as elementary unit for the tested household stoves. In total, 28 fuel/stove combinations were tested. Except those stoves using piped gas fuels, which were measured in actual homes, all other fuel/ stove combinations were tested in a simulated village kitchen house at Tsinghua University's rural campus about $50 \mathrm{~km}$ from Beijing.

The $28 \mathrm{fuel} /$ stove combinations tested are shown in Table 1. Within each fuel category, a few fuel varieties were tested. Wood fuels and crop residues were obtained from a local market in a small town near Tsinghua University's rural campus. Brush wood refers to thin branches of brushes which normally grow faster than trees. Brush wood is usually cheaper than fuel wood which is normally harvested from mature trees or their big branches (e.g., eucalyptus, acacia, oak, pine, popular, willows, etc). Maize residue and wheat residue refer to dried corn stalks and wheat straws, respectively. Except unprocessed coal powder from a specific coal mine in Shanxi Province, all the other coals were obtained in local markets near Beijing. Washed coal was prepared by soaking unprocessed coal in clean water for $24 \mathrm{~h}$, a typical practice in China to reduce sulfur content of raw coal. After washing, the coal powder was sun dried. Coal briquettes, or coal balls, are made of coal powder and clay. Honeycomb coal briquettes, also made of coal powder and clay, are named so due to their honeycomb-like shape. Elemental compositions of the tested solid fuels are shown in Table 2. All solid fuels were procured in one lot, sun-dried, and stored in a large storage room for at least 4 weeks prior to the tests.

Kerosene is a middle distillate from petroleum refining and is in liquid form under normal atmospheric conditions. Carbon, hydrogen, and oxygen content of the kerosene tested were 85.6, 13.0, and $<0.5 \%$ (by weight), respectively. Liquid petroleum gas, (LPG), another product of petroleum refining, is available in bottles and is in gaseous form under normal atmospheric conditions. The tested LPG consisted of $26.7 \%$ propane, $18.8 \%$ butane, $43.4 \%$ butene, and $11.1 \%$ of other hydrocarbons (by volume). Coal gas is synthesized from coal gasification and distributed locally to households through pipelines. 
Table 1

Description of the fuel/stove combinations tested in China

\begin{tabular}{|c|c|c|c|}
\hline \multirow{2}{*}{$\begin{array}{l}\text { Serial } \\
\#\end{array}$} & \multirow{2}{*}{$\begin{array}{l}\text { Symbol } \\
\text { fuel/stove }\end{array}$} & \multicolumn{2}{|l|}{ Description } \\
\hline & & Fuel & Stove \\
\hline 1 & Brush-Brick-v & Brush wood & brick stove with a flue \\
\hline 2 & Brush-Imp-v & Brush wood & improved brick stove with a flue \\
\hline 3 & Brush-India & Brush wood & metal stove without flue (from India) \\
\hline 4 & Wood-Brick-v & Fuel wood & same as \#1 \\
\hline 5 & Wood-Imp-v & Fuel wood & same as \#2 \\
\hline 6 & Wood-India & Fuel wood & same as \#3 \\
\hline 7 & Maize-Brick-v & Maize residue & same as \#1 \\
\hline 8 & Maize-Imp-v & Maize residue & same as \#2 \\
\hline 9 & Wheat-Brick-v & Wheat residue & same as \# 1 \\
\hline 10 & Wheat-Imp-v & Wheat residue & same as \#2 \\
\hline 11 & CoalBriq-metal & Coal briquette & metal coal stove without flue \\
\hline 12 & CoalBriq-metal-v & Coal briquette & metal coal stove with a flue \\
\hline 13 & Honey-imp & Honeycomb coal briquette & improved metal coal stove without flue \\
\hline 14 & Honey-metal & Honeycomb coal briquette & same as \# 11 \\
\hline 15 & Honey-metal-v & Honeycomb coal briquette & same as \#12 \\
\hline 16 & Honey(s)-metal-v & $\begin{array}{l}\text { Honeycomb coal from a special coal mine } \\
\text { in Shanxi province }\end{array}$ & same as \# 12 \\
\hline 17 & Coal-brick-v & Unprocessed coal (coal powder) & same as \# 1 \\
\hline 18 & Coal-metal & Unprocessed coal (coal powder) & same as \# 11 \\
\hline 19 & Coal-metal-v & Unprocessed coal (coal powder) & same as \#12 \\
\hline 20 & Coal(s)-metal-v & $\begin{array}{l}\text { Coal powder from a special coal mine } \\
\text { in Shanxi province }\end{array}$ & same as \# 12 \\
\hline 21 & WashCoal-metal-v & Washed coal powder & same as \# 12 \\
\hline 22 & Kero-press & Kerosene & kerosene pressure stove without flue \\
\hline 23 & Kero-wick & Kerosene & kerosene wick stove without flue \\
\hline 24 & LPG-IR & Liquefied petroleum gas & LPG stove with an infrared head without flue \\
\hline 25 & LPG-trad & Liquefied petroleum gas & LPG traditional stove without flue \\
\hline 26 & NaturalGas-IR & Natural gas & gas stove with an infrared head without flue \\
\hline 27 & NaturalGas-trad & Natural gas & traditional gas stove without flue \\
\hline 28 & CoalGas-trad & Coal gas & traditional gas stove without flue \\
\hline
\end{tabular}

Note: flue code: $\mathrm{v}=$ vented, i.e., with flue.

The lines in the table segregate the fuel category: \# 1-6 wood; \# 7-10, crop residue; \# 11-21, coal; \# 22-23, kerosene; and \# 24-28, gas.

The tested coal gas consisted of $61.4 \%$ hydrogen, $23.8 \%$ $\mathrm{CH}_{4}, 5.6 \% \mathrm{CO}, 2.7 \% \mathrm{CO}_{2}, 3.7 \%$ nitrogen, $0.1 \%$ oxygen, and $2.7 \%$ NMHC (by volume). The natural gas tested in a Beijing home was transported from a natural gas field located more than $1000 \mathrm{~km}$ northwest of Beijing and consisted of $84.5 \% \mathrm{CH}_{4}, 0.8 \% \mathrm{CO}_{2}, 0.7 \%$ nitrogen, and $14 \%$ NMHC (by volume).

The brick and improved stoves in Table 1 were built on the floor with their flues attached to a side wall of the simulated kitchen (a typical arrangement found in village kitchens). The India stove was a portable metal nonchimney stove made in India and transported to China for the study. All the other stoves were purchased from local markets. Although similar to the (traditional) stoves in overall shape and structure, the improved stoves had a better design to increase stove thermal efficiencies $(\mathrm{Gu}$ et al., 1991). The kerosene wick stove tested was a portable, one-burner stove. This was the most popular type of kerosene stove in China. The kerosene pressure stove, a single-burner pumping stove, is much less popular and more costly than the kerosene wick stove in China. All stoves used for burning gaseous fuels were standard multiple-burner gas ranges, although only one burner was used for the tests. The infrared head, a circular device attached around the burner under the pot is designed to convert a portion of the heat released into the surrounding air into infrared radiation which can then irradiates the pot bottom.

\subsection{Carbon balance approach}

The mass balance of carbon in fuel combustion process can be described as follows,

$$
C_{\mathrm{f}}-C_{\mathrm{a}}=C_{\mathrm{CO}_{2}}+C_{\mathrm{CO}}+C_{\mathrm{CH}_{4}}+C_{\mathrm{TNMHC}}+C_{\mathrm{TSP}}
$$


Table 2

Composition of solid fuels tested

\begin{tabular}{|c|c|c|c|c|c|}
\hline Fuel & Carbon $(\%)$ & Hydrogen $(\%)$ & Sulfur $(\%)$ & Water $(\%)$ & $\operatorname{Ash}(\%)^{\mathrm{a}}$ \\
\hline Brush wood & 44.48 & 5.39 & 0 & 7.65 & 1.75 \\
\hline Fuel wood & 45.58 & 4.74 & 0 & 7.98 & 1.16 \\
\hline Maize residue & 34.81 & 3.56 & 0 & 9.09 & 6.28 \\
\hline Wheat residue & 40.34 & 5.29 & 0 & 7.26 & 8.71 \\
\hline Coal briquette & 49.39 & 0.56 & 0.257 & 3.48 & 43.35 \\
\hline Honeycomb coal briquette & 63.65 & 0.28 & 0.166 & 3.94 & 25.36 \\
\hline $\begin{array}{l}\text { Honeycomb coal from a special coal mine } \\
\text { in Shanxi province }\end{array}$ & 54.33 & 2.6 & 0.94 & 2.68 & 35.8 \\
\hline Unprocessed coal powder & 73.76 & 4.38 & 0.852 & 2.08 & 7.2 \\
\hline $\begin{array}{l}\text { Coal powder from a special coal mine } \\
\text { in Shanxi Province }\end{array}$ & 62.55 & 2.66 & 0.98 & 1.00 & 29.87 \\
\hline Washed coal & 77.75 & 4.52 & 0.35 & 4.73 & 3.7 \\
\hline
\end{tabular}

${ }^{a}$ Ash content of fuel, not the actual ash generated by the combustion.

where $C_{\mathrm{f}}$ is the carbon mass in the fuel, $C_{\mathrm{a}}$ the carbon mass in the ash including remaining unburned solid fuel, or char, $\mathrm{C}_{\mathrm{CO}_{2}}, \ldots, \mathrm{C}_{\mathrm{TSP}}=$ carbon mass in $\mathrm{CO}_{2}, \ldots$, and TSP, respectively. It is assumed, in Eq. (1), that the carbon mass in other organic emissions than TNMHC and $\mathrm{CH}_{4}$ is negligible. A small amount of lighter fluid was used to start burning of some of the solid fuels. In this case, the carbon mass of the lighter fluid was added to the left side of the Eq. (1). Rearranging Eq. (1) leads to:

$$
\begin{aligned}
\frac{C_{\mathrm{f}}-C_{\mathrm{a}}}{C_{\mathrm{CO}_{2}}} & =1+\frac{C_{\mathrm{CO}}}{C_{\mathrm{CO}_{2}}}+\frac{C_{\mathrm{CH}_{4}}}{C_{\mathrm{CO}_{2}}}+\frac{C_{\mathrm{TNMHC}}}{C_{\mathrm{CO}_{2}}}+\frac{C_{\mathrm{TSP}}}{C_{\mathrm{CO}_{2}}} \\
& =1+K,
\end{aligned}
$$

where

$K=\frac{C_{\mathrm{CO}}}{C_{\mathrm{CO}_{2}}}+\frac{C_{\mathrm{CH}_{4}}}{C_{\mathrm{CO}_{2}}}+\frac{C_{\mathrm{TNMHC}}}{C_{\mathrm{CO}_{2}}}+\frac{C_{\mathrm{TSP}}}{C_{\mathrm{CO}_{2}}}$,

where $C_{\mathrm{CO}} / C_{\mathrm{CO}_{2}}, C_{\mathrm{CH}_{4}} / C_{\mathrm{CO}_{2}}, C_{T N M H C} / C_{\mathrm{CO}_{2}}, \mathrm{C}_{\mathrm{TSP}} / C_{\mathrm{CO}_{2}}$ are called the emission ratios of $\mathrm{CO}, \mathrm{CH}_{4}$, TNMHC, and TSP-C, respectively. $K$ is the sum of the emission ratios (relative to $\mathrm{CO}_{2}$ ) for $\mathrm{CO}, \mathrm{CH}_{4}$, etc. and is assumed to represent all products of incomplete combustion (PICs). Thus,

$C_{\mathrm{CO}_{2}}=\frac{C_{\mathrm{f}}-C_{\mathrm{a}}}{1+K}$.

Since the emission factor, $E_{\mathrm{m}}$, for a pollutant is defined as mass of the pollutant emitted per mass of fuel burned $(M)$, the emission factor for carbon in $\mathrm{CO}_{2}\left(\mathrm{CO}_{2}-\mathrm{C}\right)$ can be calculated from the following equations,

$E_{\mathrm{m}, \mathrm{CO}_{2}-\mathrm{C}}=\frac{C_{\mathrm{f}}-C_{\mathrm{a}}}{(1+K) M}$ and the emission factor of $\mathrm{CO}_{2}$ is

$E_{\mathrm{m}, \mathrm{CO}_{2}}=\frac{C_{\mathrm{f}}-C_{\mathrm{a}}}{(1+K) M} f_{\mathrm{CO}_{2}}$,

where $f_{\mathrm{CO}_{2}}$ is a conversion factor from carbon mass to the compound mass. Since the molecular weight of $\mathrm{CO}_{2}$ is 44 and that of carbon is $12, f_{\mathrm{CO}_{2}}=3.67$. The emission factors for any other pollutant found in the flue gas, $X$, can now be calculated easily from the $\mathrm{CO}_{2}$ emission factor $\left(E_{\mathrm{m}, \mathrm{CO}_{2}}\right)$ and its molar emission ratio to $\mathrm{CO}_{2}$ :

$E_{\mathrm{m}, X}=\left(E_{\mathrm{m}, \mathrm{CO}_{2}}\right) \frac{C_{X}}{C_{\mathrm{CO}_{2}}} \cdot \frac{(\mathrm{MW})_{X}}{44}$

where $E_{\mathrm{m}, X}$ is the emission factor of $X, C_{x}$ is the molar concentration of $X$, and $(\mathrm{MW})_{X}$ is the molecular weight of $X$.

One of the advantages of using the carbon balance model to determine emission factors is that this approach requires the measurement of emission ratios, but not absolute carbon mass, of the emitted airborne species. This means that the sampling probe position can be relatively flexible in the flue gas stream, because it can be reasonably assumed that all airborne pollutants experience the same dilution factor at a sampling position in the flue gas.

Since different amounts of fuels are needed for the same cooking task using different fuel/stove combinations, task-based emission factors (mass of pollutant per cooking task) rather than the fuel mass based is a better performance index to compare the air pollution potential of different fuel/stove combinations (Joshi et al., 1989; Zhang and Smith, 1996). In two previous papers, the standard cooking task was defined as one that would deliver $879 \mathrm{~kJ}$ heat to the cooking vessel (Ahuja et al., 1987; Joshi et al., 1989). However, "standard task" is 
a rather slippery concept, there is obviously no "gold" definition for it. We think emission factor per "delivered energy" (rather than per cooking task, as used conventionally) is more appropriate to use for the comparison of emissions among different stoves. In this paper, therefore, we report the task-based emission factors as mass of a pollutant emitted per unit energy (1 $\mathrm{MJ})$ delivered to the pot. We chose $1 \mathrm{MJ}$ as unit energy because it is still true that $1 \mathrm{MJ}$ of delivered heat is roughly what a typical one-pot family meal would require in traditional biomass-using household (Ahuja et al., 1987). The conversion from emissions per $\mathrm{kg}$ of fuel to emissions per $1 \mathrm{MJ}$ delivered energy can be achieved using the following equation:

$E_{\mathrm{e}}=\frac{E_{\mathrm{m}}}{H \cdot \eta}$,

where $E_{\mathrm{e}}$ is the delivered-energy-based emission factor (mass per $1 \mathrm{MJ}$ delivered energy); $H$ is the fuel energy content or calorific value $(\mathrm{MJ} / \mathrm{kg})$, and $\eta$ is the stove thermal efficiency $(\%) . H$ and $\eta$ were measured in the study and reported in Table 5.

\subsection{Experimental design and sampling approach}

Cooking is not a steady-state process. The most common cooking practices have different phases for fuel burning rate (power), namely high and low power phase. Unlike for gaseous fuels, the emission characteristics for solid fuels vary at different times during the burn (Smith et al., 1993; Cooper and Malek, 1982). Hence, it is necessary to choose a burn cycle that is reasonably close to the common cooking practice in the field. For the present study the "water boiling test", a procedure developed as a standard international method to compare the efficiencies of different stoves, was used with slight modification (VITA, 1985). The water boiling test is a relatively short, simple simulation of common cooking procedure in which a standard quantity of water is used to simulate food. The test includes "high power" and "low power" phases. The high power phase involves heating the standard quantity of water from the ambient temperature to boiling temperature as rapidly as possible. The low power phase follows in which the power is reduced to the lowest level needed to keep the water simmering. Except for coal burning, the burn cycles ranged from 35 to $60 \mathrm{~min}$ for all other types of fuel/stove combinations. Coal burning needs a longer cycle due to the slow burn rate especially at the initial phase of coal burning. A pot containing known amount of water was placed on a tested stove during the entire burn cycle. Collected data included those (e.g., water temperature changes, amount of vapor generated, amount of fuel burned) necessary to determine thermal parameters such as burn rate and over-all thermal efficiency of each fuel/stove combination. This procedure, therefore, has the added advantage of enabling simultaneous measurement of emissions and thermal parameters in a systematic and standard manner.

Three successful tests with complete burn cycles were conducted for each fuel/stove combination. Airborne products of combustion were collected using a sampling configuration which included, from up-stream to downstream of the sampling train, a stainless-steel probe, a filter holder, a pump (SKC Inc., USA), and a clean Tedlar bag (SKC Inc., USA). For stoves with flue, the probe was inserted in the flue. Using this sampling method may cause a measurement error because not all the emissions were passing though the flue during a complete burn cycle. A better experimental design was conducted in India by placing the flue under a hood inside which the sample was taken. However, we did not observe a significant difference between the results obtained using the two different sampling arrangements to test a coal stove. For those having no flues, the stoves were placed under a hood built for the test purpose and the probe was placed inside a hood exhaust duct. The hood method has been used previously in studies of unvented cookstoves and kerosene space heaters (Davidson et al., 1986; Lionel et al., 1986; Ballard-Tremeer and Jawurek, 1996). Filters employed to collect TSP were heattreated 37-mm quartz fiber filters (Pallflex Products Co., USA). The flow rate of sampling pump was adjusted to fill one or two 80-liter Tedlar bags throughout a whole burn cycle (i.e., from fire start to fire extinction). Indoor background samples were collected at stove mouth height near the door using the same sampling configuration.

An aliquot of air samples $(1 \mathrm{ml})$ was taken using a gastight syringe out of a filled 80-1 Tedlar bag for immediate analyses of $\mathrm{CO}_{2}, \mathrm{CO}, \mathrm{CH}_{4}$, and TNMHC in an analytical lab located in a building next to the simulated kitchen. When immediate analyses were not possible, about 21 of air was transferred from the 80-1 Tedler bag to a small (4-1 capacity) Tedlar bag using a SKC pump and Teflon tubing. All small bags were analyzed within 3 days of sample collection. Based on our test results, no significant losses of the analyzed compounds occurred from a 3-day storage in small Tedlar bags. Another aliquot of samples was taken using a pump at a flow rate of 0.2-0.4 1 $\min ^{-1}$ and Teflon tubing out of the 80-1 Tedlar bag for $\mathrm{SO}_{2}$ and $\mathrm{NO}_{x}$ analysis, respectively. $\mathrm{SO}_{2}$ was collected using an impinger containing a solution of formaldehyde, potassium biphthalate, and $\mathrm{Na}_{2}$-CDTA buffer solution. $\mathrm{NO}_{x}$ was collected using a $\mathrm{CrO}_{3}$ tube and an impinger containing a solution of $p$-aminobenzenesulfonic acid, acetic acid, and naphthyl-ethylene-diamine-hydrochloride (NEDA) (Salztman reagent). The $\mathrm{CrO}_{3}$ tube, placed in the up-stream of the impinger, was to oxidize NO to $\mathrm{NO}_{2}$. These were standard methods for sampling ambient $\mathrm{SO}_{2}$ and $\mathrm{NO}_{x}$ (SEPA, 1992). 


\subsection{Sample analysis methods}

Time, temperature, and the weight of water, fuel, and char were recorded at the beginning and end of the high and low cooking phases. For gaseous fuels, the volume of gas consumed was recorded during each experiment. Fuel energy contents and moisture contents were analyzed by a governmental laboratory at the Center for Fuel Quality Tests and Control in Beijing, Fuel, ash, and char samples were also analyzed for carbon, sulfur, ash and nitrogen contents by the same laboratory using standard fuel analysis methods. TSP concentrations were determined grametrically using the particle mass collected on the filters and the sampling volumes. One filter for each fuel/stove combination was analyzed for carbon content of TSP using a thermal-optical carbon analysis technique at Sunset Laboratory, Oregon, USA (Johnson et al., 1981; Turpin et al., 1990).

A system of gas chromatograph - flame ionization detector (FID) - methanizer was employed for analysis of $\mathrm{CO}_{2}, \mathrm{CO}$, and $\mathrm{CH}_{4}$. In this system, a carbonspherepacked column was used to separate these three compounds. The separated $\mathrm{CO}$ and $\mathrm{CO}_{2}$ were converted by hydrogen $\left(\mathrm{H}_{2}\right)$ at $375^{\circ} \mathrm{C}$ in a nickel catalytic device (the methanizer) to $\mathrm{CH}_{4}$ which was then determined by the FID. TNMHC was measured by subtracting $\mathrm{CH}_{4}$ from the total hydrocarbon (THC) which was determined as $\mathrm{CH}_{4}$ concentration using a FID and a blank GC column. The small air peak was corrected from THC peak during the analysis.

Approximately 30 min after $\mathrm{SO}_{2}$ collection, the solution in the impinger was transferred to a volumetric flask and treated (by sequentially adding) with sulfuric acid, sodium hydroxide, and para-rosaniline. After sitting at $20 \pm 2^{\circ} \mathrm{C}$ for $15 \mathrm{~min}$, the treated solution was analyzed colorimetrically at a wave length of $575 \mathrm{~nm}$. Fresh solutions of $\mathrm{Na}_{2} \mathrm{SO}_{3}$, with known $\mathrm{SO}_{2}$ equivalent concentrations, were used for constructing the calibration curves (SEPA, 1992).

After sampling, the solution in each $\mathrm{NO}_{x}$ impinger was analyzed colorimetrically at a wave length of $540 \mathrm{~nm}$. High purity sodium nitrite $\left(\mathrm{NaNO}_{2}:>99.9 \%\right)$ was used to make standard solutions and calibration curves. Gaseous $\mathrm{NO}_{x}$ concentrations were calculated based upon a known conversion factor from gaseous $\mathrm{NO}_{2}$ concentration to aqueous $\mathrm{NO}_{2}^{-}$concentration $(0.76$ for the absorbing solution used in this study) (SEPA, 1992).

\subsection{Quality controls}

For each fuel/stove combination, preliminary experiments were conducted to standardize the burn cycle and minimize the natural viability due to differences in operator behavior. These trial runs were repeatedly conducted, prior to the three planned tests for each fuel/stove combination, until a satisfactory method precision (roughly $<20 \%$ RSD for major parameters measured) was obtained. Solid fuels were collected in one lot, sun-dried and covered with plastic sheet and kept out of sunlight to avoid any changes in moisture. After each experiment, the doors and windows of the simulated ketches were opened. Several exhaust fans and side fans were switched on to clean the room properly. Char and ash remaining in each experiment for solid fuels were covered with aluminum foil and labeled for subsequent weight and carbon analysis. All Tedlar bags and Teflon tubing used in each experiment were flushed adequately with compressed clean air for at least three times before each use. Tedlar bags and Teflon tubing used for lowgrade fuels such as biomass fuels and coals were not used again. After each fuel/stove combination was tested, the probe was cleaned with DI water and ethanol.

The quartz fiber filters used were baked at $600^{\circ} \mathrm{C}$ in a clean oven for $2 \mathrm{~h}$ to remove any carbon impurities. Each filter was placed in a clean petri dish during transport and storage. Pre-sampling and post-sampling weighing of filters were made using an electronic microbalance with a sensitivity of $10^{-5} \mathrm{~g}$. Prior to weighing, all filters were equilibrated in a weighing room for at least $24 \mathrm{~h}$ with constant humidity and temperature. Approximately, one blank filter was used for every batch of 10 samples. The blank filters were heat-treated and weighed in the same fashion. The difference between any two times of blank filter weighing was within $\pm 10 \%$. The exposed filters, placed individually in a petri dish, had been stored in a freezer before they were sent for carbon analyses.

For GC analysis, two or more injections were made for each sample to insure a RSD $<10 \%$. Calibration curves for all measured compounds were made daily and had linear regression $R^{2}>0.99$. For every batch of 10 to 15 samples, a standard was spiked to assure that the peak area reading was within $\pm 10 \%$ of the previous reading. The detection limit was about $0.7-1.0 \mathrm{ppm}$ for $\mathrm{CO}_{2}, \mathrm{CO}$, $\mathrm{CH}_{4}$, and THC. The $\mathrm{SO}_{2}$ and $\mathrm{NO}_{x}$ analyses followed the similar QC procedure: Calibration curves were made freshly on a daily basis. All calibration curves had $R^{2}>0.99$. For every batch of 10 samples, a reference solution (blank) and a standard solution were spiked to assure a $\pm 10 \%$ reproducibility. The method detection limit was $20 \mu \mathrm{g} / \mathrm{m}^{3}$ for $\mathrm{SO}_{2}$ and $1.6 \mu \mathrm{g} / \mathrm{m}^{3}$ for $\mathrm{NO}_{x}$.

At least one set of parallel sampling of flue gas was conducted for each fuel type. Results from these replicate samples were generally $<20 \%$ RSD for the measured species in flue gases.

\section{Results and discussion}

\subsection{Emission ratios}

Molar emission ratios to $\mathrm{CO}_{2}$ are shown in Table 3 for the 28 fuel/stove combinations. The ratios were 


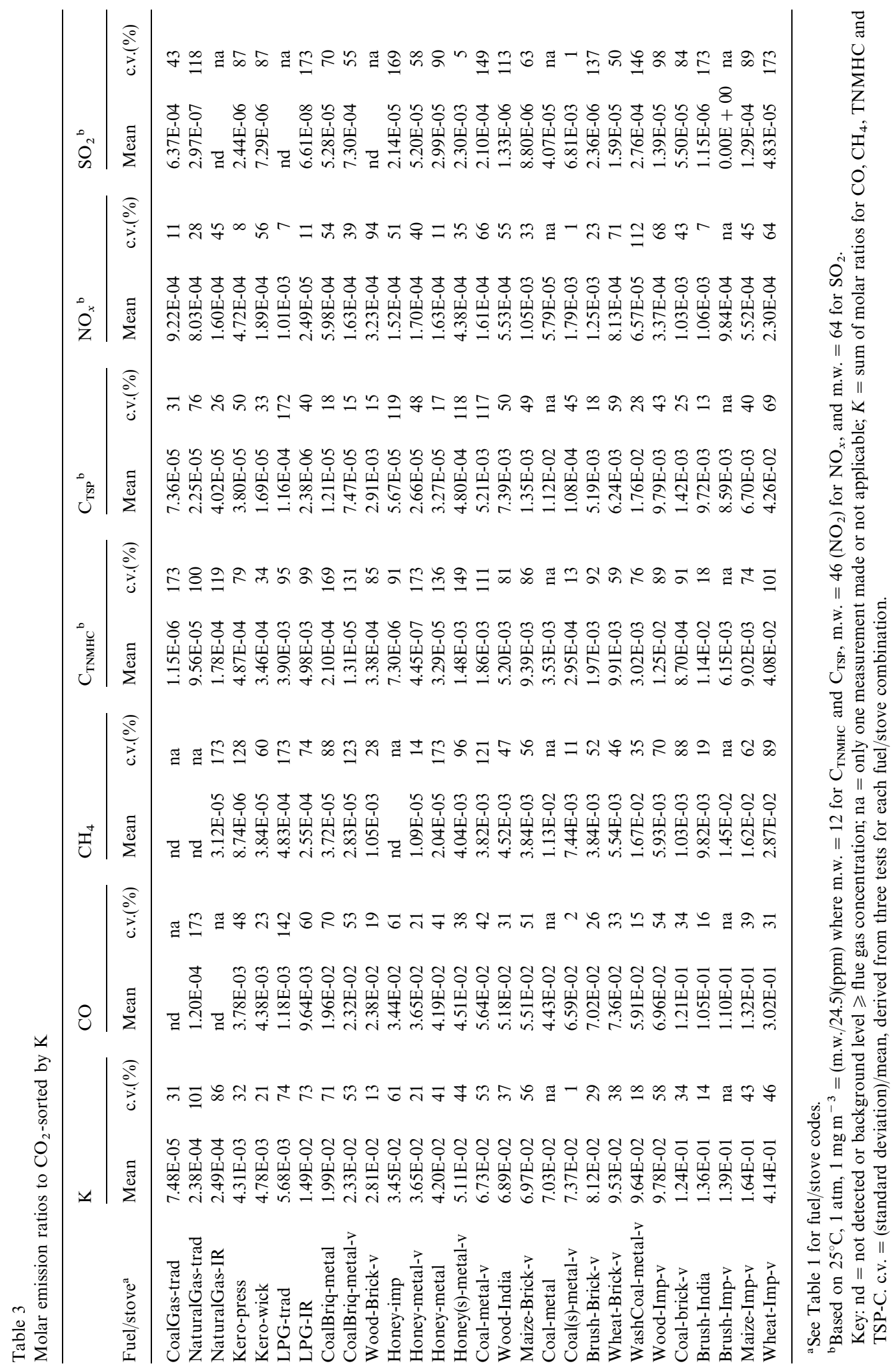


calculated using net concentrations of each reported compound and net concentrations of $\mathrm{CO}_{2}$ (net concentration equals flue gas concentration minus background concentration). Reported in Table 3 are the means and coefficients of variation (c.v.) derived from three successful tests for each fuel/stove combination. Because $\mathrm{C}_{\mathrm{TSP}}$, $\mathrm{SO}_{2}$ and $\mathrm{NO}_{x}$ were measured as $\mathrm{mg} / \mathrm{m}^{3}$, the molar ratios were calculated using conversion factors based on $25^{\circ} \mathrm{C}$ and 1 atmosphere condition (see footnotes of Table 3). The concentrations of $\mathrm{C}_{\text {TSP }}$ were obtained using measured carbon content of TSP $(\%)$ and TSP concentration $\left(\mathrm{mg} / \mathrm{m}^{3}\right) . K$ is the sum of emission ratios of all other carbon-containing species than $\mathrm{CO}_{2}$ in the flue gas and represents the emission ratio for total product of incomplete combustion (PIC). Since the ideal combustion would convert all carbon in the fuel burnt to $\mathrm{CO}_{2}$ solely, $\mathrm{K}$ is inversely proportional to the nominal combustion efficiency (Smith et al., 1999). The results shown in Table 3 indicate that the coal gas and natural gas had highest combustion efficiencies, followed by kerosene and LPG, then followed by various coals and fuel wood, and then by crop residues and brush wood, with a very wide range for K (nearly 4 order of magnitude).

\subsection{Emission factors}

The emission factors are reported on a fuel mass basis in Table 4 and on a delivered energy basis in Table 5 . (The thermal efficiency value, $\eta$, of each tested fuel/stove combination and the energy content, $H$, of each tested fuel are reported in Table 5 as well.) The means and c.v. values were derived from the three successful experiments for each of the tested fuel/stove combinations. The PIC emission factors are the summation of the emission factors for $\mathrm{CO}, \mathrm{CH}_{4}, \mathrm{C}_{\mathrm{TNMHC}}$, and TSP. $\left(\mathrm{SO}_{2}\right.$ and $\mathrm{NO}_{x}$ are not included because they do not contain carbon.) For each of the $6 \mathrm{wood} /$ stove combinations tested, two values of emission factors are reported in Tables 4 and 5: the smaller value being called instant emission factor and the larger value (reported in parentheses) being called ultimate emission factor. The reasoning for reporting the two values is as follows.

During combustion of wood in a cookstove, fuel carbon is mainly converted to TSP and gases including $\mathrm{CO}_{2}, \mathrm{CO}$, and volatile organic compounds. A small fraction of fuel carbon is diverted into bottom ash or remains as the partially burned material, char. In determining instant emission factors for the airborne components, we subtract char carbon from the fuel carbon in the carbon balance equation. The emission factors determined in this way, thus, represent the emission measures for instant wood combustion, assuming the char generated during the combustion will not be burnt later.

In reality, users of wood cookstoves usually save unburned char to be burned along with wood at the next meal or extracted and stored for later use to cook a meal entirely with the char or to use in the winter in small personal braziers for heating. In this situation, the char carbon generated through primary wood combustion would be ultimately converted to airborne carbon species entering the atmosphere. The amount of each airborne species associated with the secondary char combustion should be added to the instant emission factors to truly represent the ultimate emission measures. Since we realized this issue after having finished all the field experiments in which no tests for char combustion had been planned, we decide to use the data from several lowquality charcoal combustion measurements for calculating the ultimate emission factors, assuming that the char would have the same emission factors as the low-quality charcoal. The tests for charcoal/stove combinations were conducted in India (Smith et al., 1999). The results show that every gram of char (or $0.81 \mathrm{~g}$ carbon in the char) generated through the primary wood combustion would be converted during secondary char burning to: $0.66 \mathrm{~g}$ $\mathrm{C}_{\mathrm{CO}_{2}}$ (or $2.42 \mathrm{~g} \mathrm{CO}_{2}$ ); $0.12 \mathrm{~g} \mathrm{C}_{\mathrm{CO}}$ (or $0.28 \mathrm{~g} \mathrm{CO}$ ); $0.0059 \mathrm{~g}$ $\mathrm{C}_{\mathrm{CH} 4}$ (or $0.0079 \mathrm{~g} \mathrm{CH}_{4}$ ); $0.0068 \mathrm{~g} \mathrm{C}_{\mathrm{TNMHC}} ; 0.0020 \mathrm{~g} \mathrm{C}_{\mathrm{TSP}}$ (or $0.0024 \mathrm{~g}$ TSP); and $0.0099 \mathrm{~g}$ carbon in remaining char and ash. Note that the remaining char produced during the secondary combustion had low carbon contents ( $<21 \%$ by weight) and small quantity, i.e., too poor to be attractive as fuel. It seem justifiable, therefore, to consider this as the solid carbon that becomes part of the disposed ash and char and is thus sequestered from the atmosphere, if not permanently, at least for long periods.

The results indicate that the difference between instant emission factor and ultimate emission factor was much smaller for $\mathrm{CO}_{2}$ than for PIC, suggesting that flaming combustion of wood would be more complete than charcoal burning at a relatively steady rate.

For solid fuels, emission factors are sometimes reported on a dry fuel mass basis. Since the fuel moisture content for each tested solid fuel (crop residue, wood, and coal) was measured (see Table 2), the fuel-mass-based emission factors shown in Table 4 can be easily converted to dry-fuel-mass-based emission factors.

\subsection{Implications and potential applications of the database}

Use of this database can be expected to reduce uncertainties in estimating GHG emissions from combustion of domestic fuels in China and in other countries with similar situations, especially when stove-specific fuel consumption data are available. Unfortunately, regional or national fuel data have often not been stove-specific, perhaps partly due to the lack of such a detailed database of emission factors. We thus hope that these fuel/stove specific emission factors will stimulate the collection of stove-specific fuel data in the future to further improve the emission estimates. 


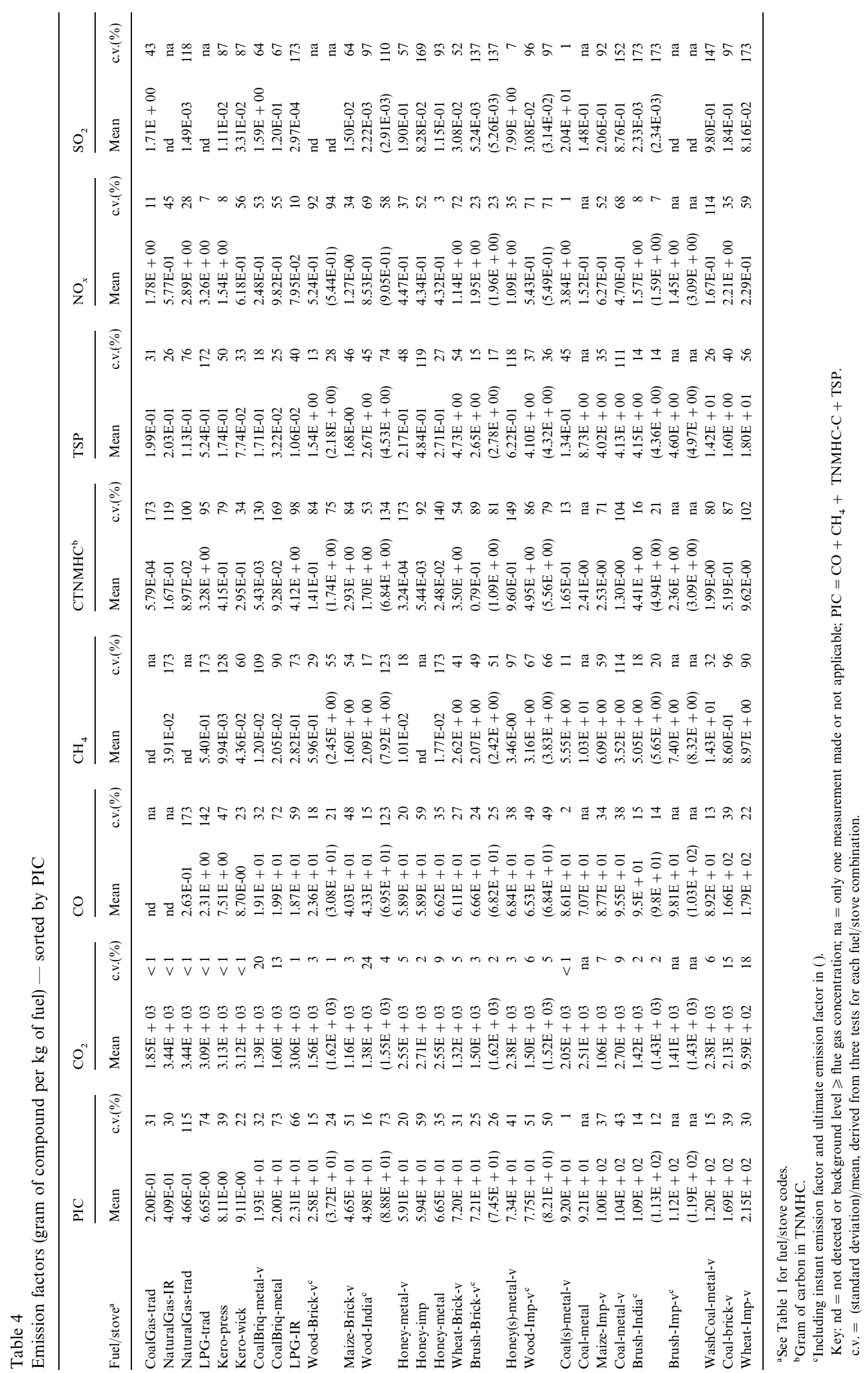




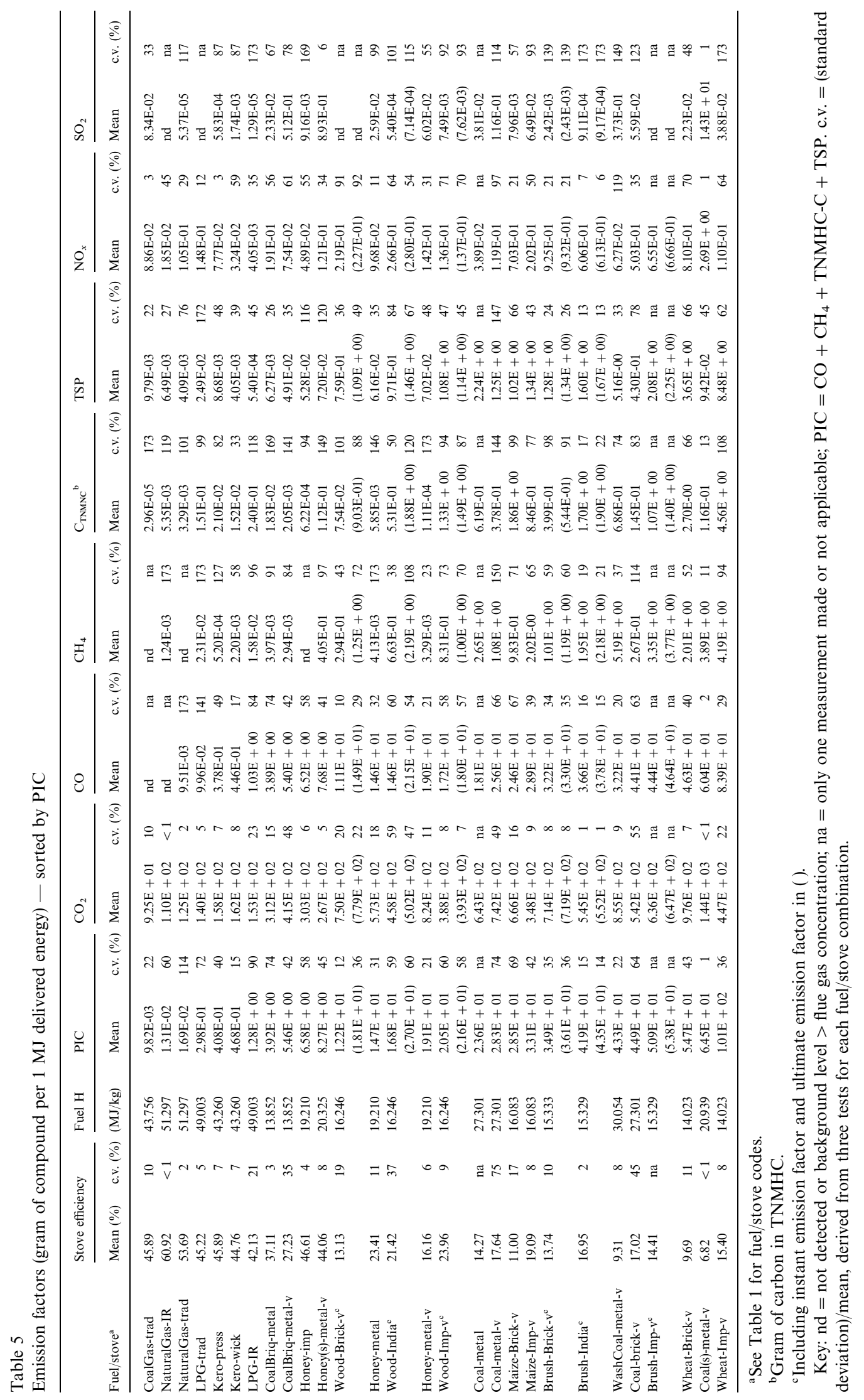


Table 6

Mean, minimum and maximum emission factors of each fuel type (gram of compound per $\mathrm{kg}$ of fuel)

\begin{tabular}{lllllllll}
\hline Fuel Type & & $\mathrm{CO}_{2}$ & $\mathrm{CO}$ & $\mathrm{CH}_{4}$ & $\mathrm{C}_{\mathrm{TNMHC}}{ }^{\mathrm{a}}$ & $\mathrm{TSP}$ & $\mathrm{NO}_{x}$ & $\mathrm{SO}_{2}$ \\
\hline Wood & Min & $9.87 \mathrm{E}+02$ & $1.97 \mathrm{E}+01$ & $3.80 \mathrm{E}-01$ & $2.57 \mathrm{E}-02$ & $1.17 \mathrm{E}+00$ & $1.23 \mathrm{E}-01$ & $\mathrm{nd}$ \\
(Instant Emission) & Mean & $1.45 \mathrm{E}+03$ & $5.87 \mathrm{E}+01$ & $2.70 \mathrm{E}+00$ & $2.27 \mathrm{E}+00$ & $3.05 \mathrm{E}+00$ & $1.16 \mathrm{E}+00$ & $7.91 \mathrm{E}-03$ \\
& Max & $1.62 \mathrm{E}+03$ & $1.11 \mathrm{E}+02$ & $7.40 \mathrm{E}+00$ & $9.68 \mathrm{E}+00$ & $5.87 \mathrm{E}+00$ & $2.77 \mathrm{E}+00$ & $6.08 \mathrm{E}-02$ \\
Wood & Min & $1.41 \mathrm{E}+03$ & $2.41 \mathrm{E}+01$ & $5.37 \mathrm{E}+01$ & $2.94 \mathrm{E}-01$ & $1.51 \mathrm{E}+00$ & $1.24 \mathrm{E}-01$ & nd \\
(Ultimate Emission $)$ & Mean & $1.52 \mathrm{E}+03$ & $6.92 \mathrm{E}+01$ & $5.06 \mathrm{E}+00$ & $4.34 \mathrm{E}+00$ & $3.82 \mathrm{E}+00$ & $1.19 \mathrm{E}+00$ & $8.21 \mathrm{E}-03$ \\
& Max & $1.63 \mathrm{E}+03$ & $1.23 \mathrm{E}+02$ & $1.99 \mathrm{E}+01$ & $1.77 \mathrm{E}+01$ & $8.73 \mathrm{E}+00$ & $2.78 \mathrm{E}+00$ & $6.24 \mathrm{E}-02$ \\
Crop Residues & Min & $8.34 \mathrm{E}+02$ & $2.36 \mathrm{E}+01$ & $4.00 \mathrm{E}-02$ & $4.64 \mathrm{E}-02$ & $1.12 \mathrm{E}+00$ & $3.93 \mathrm{E}-02$ & nd \\
& Mean & $1.13 \mathrm{E}+03$ & $8.63 \mathrm{E}+01$ & $4.56 \mathrm{E}+00$ & $4.35 \mathrm{E}+00$ & $8.05 \mathrm{E}+00$ & $7.00 \mathrm{E}-01$ & $2.16 \mathrm{E}-01$ \\
& Max & $1.37 \mathrm{E}+03$ & $2.23 \mathrm{E}+02$ & $1.59 \mathrm{E}+01$ & $1.97 \mathrm{E}+01$ & $2.90 \mathrm{E}+01$ & $2.21 \mathrm{E}+00$ & $2.64 \mathrm{E}+00$ \\
Coal & Min & $1.07 \mathrm{E}+03$ & $1.10 \mathrm{E}+01$ & nd & nd & $2.60 \mathrm{E}-02$ & $8.28 \mathrm{E}-02$ & nd \\
& Mean & $2.28 \mathrm{E}+03$ & $7.13 \mathrm{E}+01$ & $2.92 \mathrm{E}+00$ & $6.64 \mathrm{E}-01$ & $1.30 \mathrm{E}+00$ & $9.14 \mathrm{E}-01$ & $2.67 \mathrm{E}+00$ \\
& Max & $2.91 \mathrm{E}+03$ & $2.10 \mathrm{E}+02$ & $1.69 \mathrm{E}+01$ & $6.90 \mathrm{E}+00$ & $1.00 \mathrm{E}+01$ & $3.86 \mathrm{E}+00$ & $2.05 \mathrm{E}+01$ \\
Kerosene & Min & $3.12 \mathrm{E}+03$ & $2.37 \mathrm{E}+00$ & nd & $9.18 \mathrm{E}-02$ & $4.61 \mathrm{E}-02$ & $2.18 \mathrm{E}-01$ & nd \\
& Mean & $3.13 \mathrm{E}+03$ & $7.39 \mathrm{E}+00$ & $2.48 \mathrm{E}-02$ & $3.92 \mathrm{E}-01$ & $1.34 \mathrm{E}-01$ & $1.10 \mathrm{E}+00$ & $2.49 \mathrm{E}-02$ \\
& Max & $3.13 \mathrm{E}+03$ & $1.09 \mathrm{E}+01$ & $6.24 \mathrm{E}-02$ & $9.21 \mathrm{E}-01$ & $2.83 \mathrm{E}-01$ & $1.69 \mathrm{E}+00$ & $6.31 \mathrm{E}-02$ \\
Gases & Min & $1.85 \mathrm{E}+03$ & nd & nd & nd & nd & $7.23 \mathrm{E}-02$ & nd \\
& Mean & $2.98 \mathrm{E}+03$ & $3.72 \mathrm{E}+00$ & $1.37 \mathrm{E}-01$ & $1.60 \mathrm{E}-00$ & $2.61 \mathrm{E}-01$ & $1.76 \mathrm{E}+00$ & $3.30 \mathrm{E}-01$ \\
& Max & $3.44 \mathrm{E}+03$ & $3.13 \mathrm{E}+01$ & $1.62 \mathrm{E}+00$ & $8.79 \mathrm{E}+00$ & $1.62 \mathrm{E}+00$ & $4.51 \mathrm{E}+00$ & $2.54 \mathrm{E}+00$ \\
\hline
\end{tabular}

${ }^{\mathrm{a}} \mathrm{Gram}$ of carbon in TNMHC.

Key: $\mathrm{nd}=$ not detected or background level $>$ flue gas concentration.

When stove-specific fuel data are not available, one may use fuel-specific emission factors for emission estimates. For this purpose, we have summarized in Table 6 the range and mean values of the emission factors measured for the five types of fuels.

The results, verifying the preliminary findings from the pilot study (Smith et al., 1993), show solid fuels (biomass and coal) are typically burned with substantial production of PIC. Some fuel/stove combinations diverted more than $10 \%$ (up to $25 \%$ for Wheat-Imp-v) of the fuel carbon into PIC. No biomass stove produced less than $4 \%$ (ultimate emission) of original fuel carbon as PIC. Greenhouse analyses of human fuel use often assume that renewably harvested biomass fuels do not contribute to global warming, because the released carbon is entirely recycled through photosynthesis in growing biomass that replaces the burned biomass. Even under renewable harvesting, however, the gases released as PIC contribute to global warming because of their higher radiative forcing than $\mathrm{CO}_{2}$ or their indirect greenhouse effects. (Direct GHGs emitted from fuel combustion include $\mathrm{CO}_{2}, \mathrm{CH}_{4}$, $\mathrm{N}_{2} \mathrm{O}$ and indirect GHGs include $\mathrm{CO}, \mathrm{NO}_{x}$, etc.) (Hayes and Smith, 1994; IPCC, 1990,1995). Thus, biomass fuels have the potential to produce net global warming commitment even when grown renewably due to the contribution of non- $\mathrm{CO}_{2}$ GHGs.

The results show that all the biomass stoves (as well as most coal stoves) tested had substantially lower thermal efficiencies than those using liquid and gaseous fuels (see
Table 5). In addition, the solid fuels had substantially lower energy contents than liquid and gaseous fuels (see Table 5). As a result, the total PIC and $\mathrm{CO}_{2}$ emissions per unit delivered energy were substantially greater from burning solid fuels. In general, the ranking follows what has been called the "energy ladder" from lower to higher quality fuels, i.e., emissions decrease and efficiencies increase in the following order: crop residues, brush wood $>$ fuel wood $>$ kerosene $>$ gas (Smith and Liu, 1994). The ranking for coal was largely depending on the specific coal types and stove designs.

The data shown in Table 5 can be used to quantitatively assess both GHG and health benefits that can be brought through switching usage from a lower-quality fuel (stove) to a higher-quality one. For example, using Wood-Brick-v to replace Wheat-Brick-v (i.e., same stove but different fuel type) to perform a same cooking task (i.e., to deliver $1 \mathrm{MJ}$ energy to the pot) would reduce emissions of $\mathrm{CO}_{2}$ by a factor of $1.3, \mathrm{CH}_{4}$ by $1.6, \mathrm{CO}$ by 3.1 , TNMHC by $3.1, \mathrm{NO}_{x}$ by 3.5 , TSP by 3.3 , and total PIC by 3. Comparing PIC emissions from pairs of traditional and improved biomass stoves using the same type of fuel (wood-Brick-v vs. wood-Imp-v; Brush-Brick-v vs. Brush-Imp-v; Maize-Brick-v vs. Maize-Imp-v; WheatBrick-v vs. Wheat-Imp-v), we have found, interestingly, that the improved stoves tend to generate greater PIC emissions (see Table 5). As shown in Table 5, it is true that the improved stoves had higher overall stove efficiencies. However, the overall stove efficiency is the 
product of combustion efficiency and heat transfer efficiency. The increase in overall stove efficiency for the so-called improved stoves is often achieved mainly by increasing the heat transfer efficiency (e.g., using tight insulation) which may consequently reduce the combustion efficiency (Smith, 1987). A decreased combustion efficiency could lead to less complete combustion and emit more PICs. Therefore, an integrated assessment of GHG emissions, thermal efficiency, and health impact can provide more balanced, fair, and complete evaluation of stoves and other combustion devices than only considering one of these three important aspects.

\section{Acknowledgements}

We greatly appreciate the assistance of Prof. X. Weng and Prof. D. Qiu of Tsinghua University, who unfortunately passed away unexpectedly. We also appreciate the assistance of Mr. Cheng and other staff at Tsinghua University. Professors J. Li, Z. Yu, X. Li, and H. Gao of Peking University performed $\mathrm{SO}_{2}$ and $\mathrm{NO}_{x}$ analyses. Mr. R. Amin, Mr. C. Fan, and Ms. S. Tsai assisted in data processing. Our colleagues at Tata Energy Research Insitute (TERI) in New Dehli, India provided a test stove and coordinated the field work in China and India. Their efforts are appreciated. This study was funded by the US EPA through a cooperative agreement with East-West Center in Hawaii. Dr. J. Zhang's research is supported in part by the NIEHS Center Grant ES05022-10. This paper has not gone through official EPA review procedures and thus should not be considered to have EPA official approval.

\section{References}

Ahuja, D.R., Joshi, V., Smith, K.R., Venkataraman, C., 1987. Thermal performance and emission characteristics of unvented biomass-burning cookstoves: a proposed standard method for evaluation. Biomass 12, 247-270.

Ballard-Tremeer, G., Jawurek, H.H., 1996. Comparison of five rural wood-burning cooking devices: efficiencies and emissions. Biomass and Bioenergy 11, 419-430.

Cofer, W.R., Levine, J.S., Winstead, E.L., Stocks, B.J., Cahoon, D.R., Pinto, J.P., 1993. Trace gas emissions from tropical biomass fires: Yucatan Peninsula. Mexico. Atmospheric Environment 27A, 1903-1907.

Cooper, J.A., Malek, D. (Eds.). 1982. Residential Solid Fuels: Environmental Impacts and Solutions. Oregon Graduate Center, Beaverton, Oregon.

Crutzen, P.J., Andreae, M.O., 1990. Biomass burning in the tropics: impact on atmospheric chemistry and biogeochemical cycles. Science 250, 1669-1678.

Davidson, C., Borrazzo, J.E., Hendrickson, C.T., 1986. Pollutant emission factors for gas stoves: a literature survey. Report CR-812543-01-0. US EPA, Research Triangle Park, NC.
FAO (Food and Agriculture Organization), 1987. Yearbook of Forest Products, Rome, Italy.

Gu, S., Huang, K., Qiu, D., Smith, K.R., 1991. 100-Million improved cookstoves in China: how was it done? Country Study No. 1, Global Review of Improved Cookstove Programs. Environment and Policy Institute, East-West Center, Honolulu, HI, USA.

Hayes, P., Smith, K.R., 1994. The Global Greenhouse Regime: Who Pays? Earthscan, London, UK.

IPCC (Inter-governmental Panel on Climate Change), 1997. In: Houghton, J.T. et al., (Ed.), Guidelines for National Greenhouse Gas Inventories: Reference Manual (Revised 1996). Vol. 3. Bracknell, UK.

IPCC (Inter-governmental Panel on Climate Change), 1995. Radiative Forcing of Climate Change, Cambridge University Press, UK.

IPCC (Inter-governmental Panel on Climate Change), 1990. Climate Change: the IPCC Scientific Assessment. Cambridge University Press, UK.

Jenkins, B.M., Turn, S.Q., Williams, R.B., 1992. Atmospheric emissions from agricultural burning in California: determination of burn fractions, distribution factors, and crop-specific contributions. Agriculture, Ecosystems and Environment 38, 313-330.

Johnson, R.L., Shah, J.J., Cary, R.A., Huntzicher, J.J., 1981. An automated thermal-optical method for the analysis of carbonaceous aerosol in ACS Symposium Series No. 167, Atmospheric Aerosol: Source/Air Quality Relationships. Eds., E.S. Macias and P.K. Hopke.

Joshi, V., Venkataraman, C., Ahuja, D.R., 1989. Emissions from burning biofuels in metal cookstoves. Environmental Management 13, 763-772.

Levine, J.S. (Ed.) 1996. Biomass Burning and Global Change. Vol. 1\&2, MIT Press, Cambridge, MA, USA.

Lionel, T., Martin, R.J., Brown, N.J., 1986. A comparative study of combustion in kerosene heaters. Environmental Science and. Technology 20, 78-85.

SEPA (State Environmental Protection Administration of China), 1992. Standardized Environmental Monitoring and Analysis Methods. SEPA, Beijing, China.

Smith, K.R., 1987. Biofuels, Air Pollution, and Health. Plenum Publishing Corp., Plenum Press, New York.

Smith, K.R., Liu, Y., 1994. Indoor air pollution in developing countries. In: Epidemiology of Lung Cancer, Samet, J.M. (Ed.), Lung Biology in Health and Disease Series. Vol. 74, Marcel Dekker, Inc., New York. p.p. $151-184$.

Smith, K.R., Uma, R., Kishore, V.V.N., Lata, K., Joshi, V., Zhang, J., Rasmussen, R.A., Khalil, M.A.K., Thorneloe, S.A., 1999. Greenhouse Gases from Small-scale Combustion Devices in Developing Countries, Phase IIa: Household Stoves in India. Office of Research and Development, US EPA, Washington, DC, USA.

Smith, K.R. Khalil, M.A.K., Rasmussen, R.A., Thorneloe, S.A., Manegdeg, F., Apte, M., 1993. Greenhouse gases from biomass and fossil fuel stoves in developing countries: a Manila pilot study. Chemosphere 26, 479-505.

Turpin, B.J., Carey, R.A., Huntzicker, J.J., 1990. An in situ, time-resolved analyzer for aerosol and organic carbon. Journal of Aerosol Science and Technology 12, 161-167. 
VITA (Volunteers in Technical Assistance, Inc.), 1985. Testing The Efficiency of Wood-burning Cookstoves: International Standards, Arlington, VA, USA.

Wang, Q.H., 1994. Investigation of rural crop straw utlization in China. Rural Eco-environment 10, 67-71.
Ward, D.E., Hardy, C.C., 1991. Smoke emissions from wildland fires. Environmental International 17, 117-134.

Zhang, J., Smith, K.R., 1996. Hydrocarbon emissions and health risks from cookstoves in developing countries. Journal of Exposure Analysis and Environmental Epidemiology 6, 147-161. 